\title{
A Comparative Analysis on Controlling Speed of Universal Motor by using Fuzzy and ANFIS Controller
}

\author{
Aisha Jilani \\ Department of Electrical \\ Engineering \\ Lahore College for Women \\ University, Jail Road, Lahore, \\ Pakistan
}

\author{
I. Ahmad \\ Department of Electrical \\ Engineering \\ Lahore College for Women \\ University, Jail Road, Lahore, \\ Pakistan
}

\author{
S. Omar Jilani \\ Department of Electrical \\ Engineering \\ University of Lahore \\ Raiwand Road, Lahore, \\ Pakistan
}

\begin{abstract}
Machines have comforted human beings in every walk of life such as scientifically, economically as well as socially. Machines consists of immotile as well certain rotating parts which combine to reduce human efforts into well-founded and pertinent work for example pulleys, blenders,, compressors etc. For every advanced technology of machines its different parameters are needed to be controlled for a competent, productive and faultless system. This paper aims on careful investigation of two advanced type of approaches for controlling speed of universal motor. These two approaches namely Fuzzy technique and ANFIS technique are employed as powerful mechanisms for varying speed based on output graph of step response versus time. A comparative evaluation is then done on the basis of two most important parameters of machines named as percentage overshoot and settling time. Comparative analysis aids in determining the best methodology to be applied in everyday applications for producing unerring, authenticated and unimpeachable systems.
\end{abstract}

\section{Keywords}

Universal motor, Fuzzy Controller, ANFIS controller, Percentage overshoot, Rise time

\section{INTRODUCTION}

A universal motor is more related to $\mathrm{DC}$ drive than to $\mathrm{AC}$ drive. A universal motor is defined as a series wound drive that functions by either AC or DC power. Output response can be maximized and losses can be minimized by laminating stator windings and field poles. Its construction can be considered similar to DC permanent magnet motor however its stator is not a permanent magnet but an electromagnet. Everyday applications of universal motors include hair dryers, washing machines, sanders, vacuum cleaners etc. The speed of universal motor usually depends upon its load. For heavy load, it runs at low speed and for light load, its speed is much higher. Practically speed of universal motor can be controlled in various ways such as by variable resistance method, by changing field strength etc. In this research work, two different approaches are used to control the speed of universal motor and then a comparative evaluation of both methods have been done to select the best approach to be build flawless, irreproachable, valuable and impeccable system.

\section{BACKGROUND}

Machines have been serving humanity for thousands of years starting from simpler lever, wedge, and wheel and axle to complex and sophisticated appliances such as refrigerators, air conditions, microwave ovens etc. Machines have been classified on the basis of their applications into different branches such as computing machines, electronics machines, molecular machines etc. Due to industrial revolution, mechanization and automation have minimized human labour and efforts into ease and quiescent work. Marvellous contributions of Michael Faraday in science have classified machines into generators and motors. Several researches have been done for advancement in the credibility, inerrancy and adaptability of machines. [1, 2, 3] does not focus on that why should DC motors be preferred over AC drives. Similarly, [4, $5,6,7,8]$ have not discussed that why should induction motors be opted rather than DC motors. The significance of $\mathrm{AC}$ and DC motor can be determined due to their widespread applications. On one hand if higher-voltage AC motors batteries run faster than on the other hand DC motors are cost effective and more reliable. Therefore it is better to consider Universal motor than studying AC and DC motor alone as universal motor can be steered by either AC or DC depending on the type of application and required output.

Comparative analysis of different techniques can provide us with different parameters on the basis of which we can conclude that which mechanism is best to be implemented and executed for any particular application and desirable output. No such comparative study on different approaches and methods has been considered in $[9,10]$.

Rising time and percentage overshoot are one of the most important parameters which should be considered while controlling speed of any type of motor. We always design a system for a low rising time and minimum percentage overshoot. Lessing rising time and percentage overshoot will produce a proficient and cogent system. No calculations have been made in $[11,12]$ regarding rising time which is the most important factor to be considered.

\section{METHODOLOGY}

This research work aims at controlling the most important parameter of universal motor by incorporating a control system into universal motor to improve its response and varying its speed according to the requirement of the user. This will help in building impeccable systems to be used in every walk of life.

Control systems are of many types such as proportional controller, linear control systems, proportional-integralderivative controller, Fuzzy Controller, Neural Controller, ANFIS technique etc. Such controllers can be made and implemented into different types of equipment according to the need and demand of the required application. Here, we 
have focused on two most important controllers categorized as:

- Fuzzy Controller

- ANFIS Controller

\section{SIMULATION OF FUZZY CONTROLLER ON MATLAB}

Author Fuzzy Logic controller is use to implement the best ideas of human nature into a control system. Its output creates a relationship between input and output of the system on the basis of well-defined rules such as IF-ELSE rule. The whole process of fuzzy controller involves three main steps:

- Fuzzification

- Determining overlapping rules

- Defuzzification

These steps are shown in Fig. 1. Process of fuzzification involves initialization of implementing fuzzy logic controller by selecting the 'Mamdani' or 'Sugeno' principle. Here we have selected Mamdani principle, which takes the speed and angle of input variables and determine the intersecting point of every input [13]. Hence then membership functions are selected and overlapping is defined between different input variables. Then certain rules are determined on the type of membership functions used as shown in TABLE I.

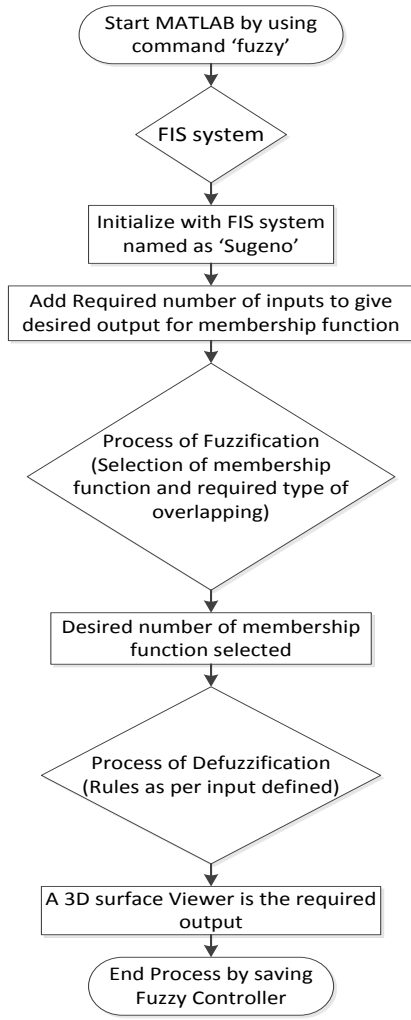

Fig. 1: Flow Chart of Simulation of Fuzzy Controller

TABLE I Rules for Universal Motor

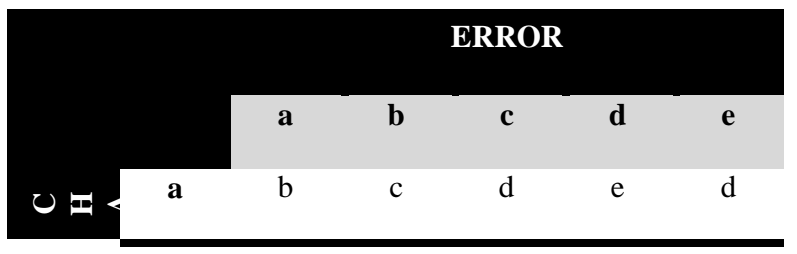

\begin{tabular}{|cccccc}
\hline b & c & d & e & d & c \\
c & d & e & d & c & b \\
d & e & d & c & b & a \\
e & d & c & b & a & b \\
\hline
\end{tabular}

A 'rule viewer' is plotted based on the already defined rules as shown in Fig. 2.

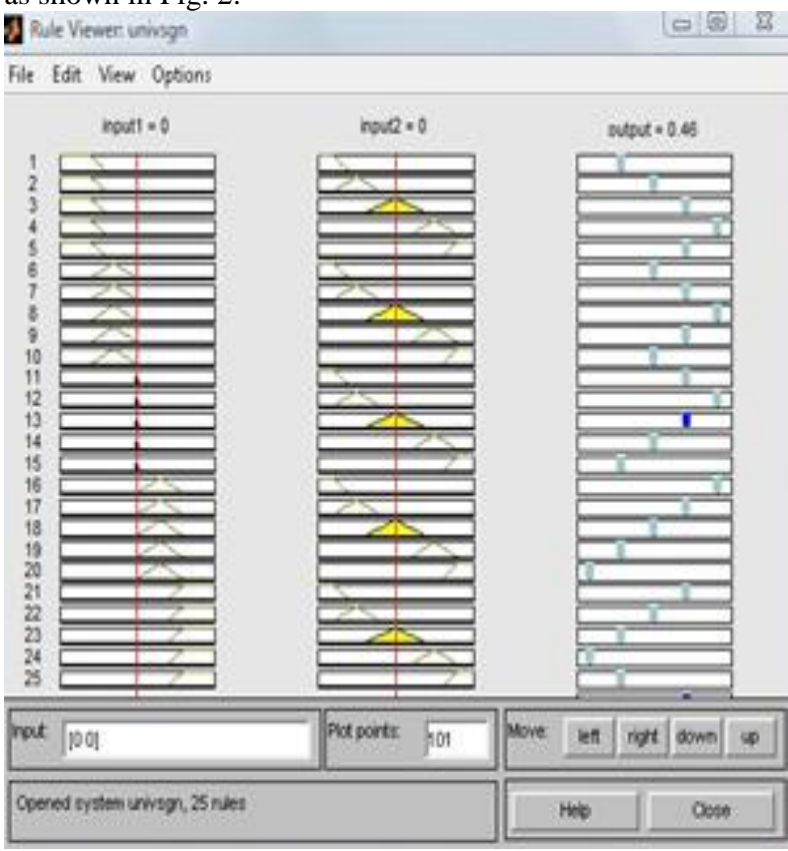

Fig. 2: Rule Viewers for Universal Motor

Defuzzification process will end the simulation of fuzzy controller by concluding its result on the basis of rules defined as per input. Our final result will be in the form of 3D surface viewer as shown in Fig. 3.

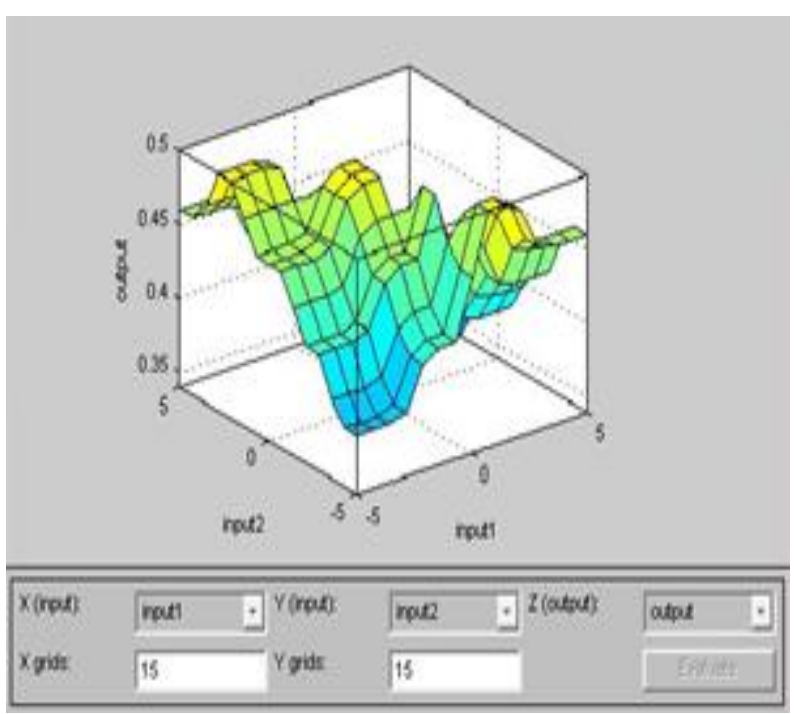

Fig. 3: Surface Viewer for Universal Motor

Simulation has been done by inserting this fuzzy technique in control system and gains of appropriate values are used as shown in in Fig. 4. 


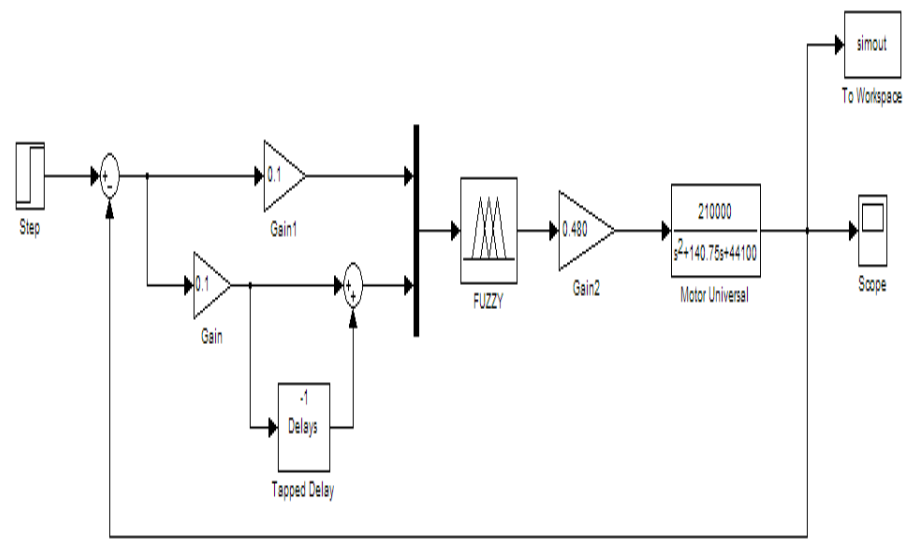

Fig. 4: Fuzzy Model for Universal Motor

The output response of the system is shown in Fig. 5, which has a certain value of overshoot and rise time.

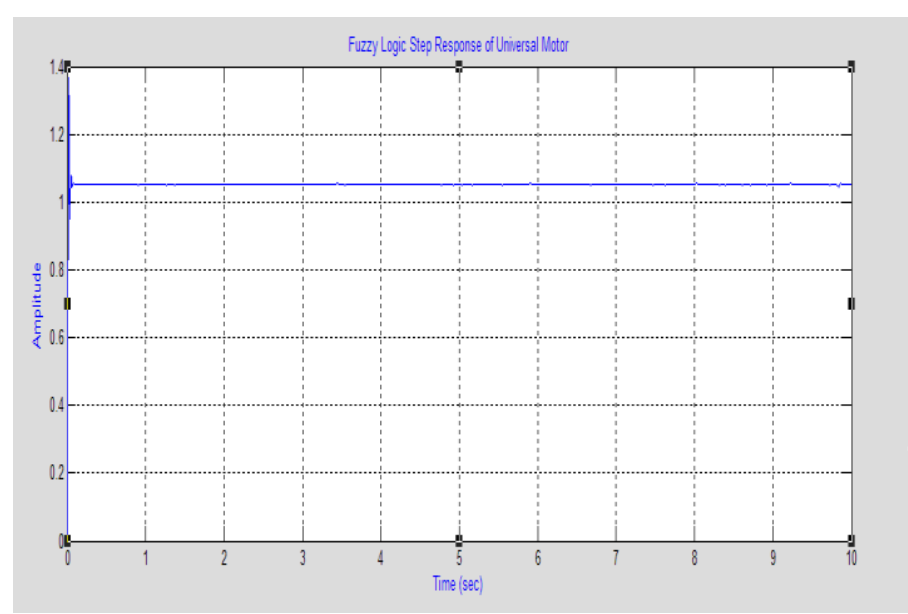

Fig. 5: Response for Universal Motor

\section{SIMULATION OF ANFIS \\ CONTROLLER ON MATLAB}

ANFIS stands for "Adaptive Network Based Fuzzy Interference System". It is an interfusion of neural network and fuzzy technique. As it is a combination of two different techniques, so it has the advantage of both controllers within a single architecture. The whole process of using ANFIS controller is shown in Fig. 6.

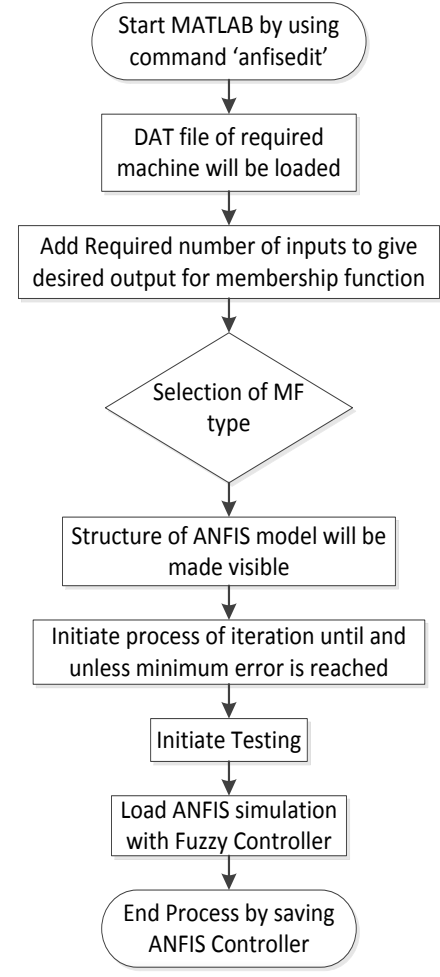

Fig. 6: Flow Chart of Simulation of ANFIS Controller

ANFIS controller can be interpreted in the MATLAB by initializing with the command 'anfisedit'. For ANFIS controller, specific data has to be loaded for any particular interpretation which will give a plot of 'Training Data' as shown in Fig. 7.

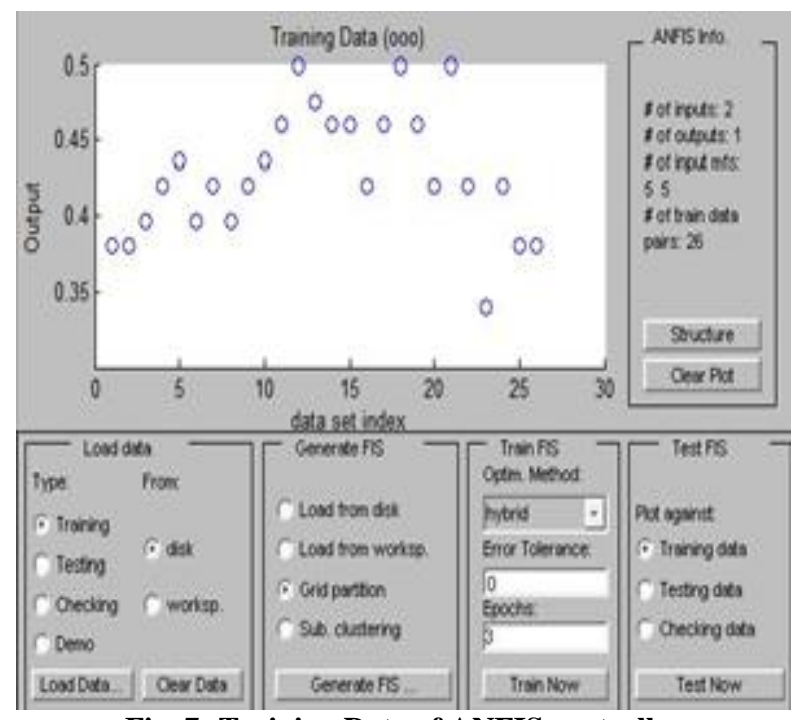

Fig. 7: Training Data of ANFIS controller

A specific data is loaded for ANFIS controller as shown in TABLE II. This data is stored in '.dat' file. 
TABLE II Specific Data for ANFIS Controller

\begin{tabular}{|c|c|c|c|}
\hline & INPUT1 & INPUT2 & OUTPUT \\
\hline & -5 & -5 & 0.38 \\
\hline & -4.5 & -5 & 0.38 \\
\hline & -2.5 & -4.5 & 0.396 \\
\hline & -2 & -4.5 & 0.42 \\
\hline & -2 & -3.5 & 0.436 \\
\hline & -3.5 & -3.5 & 0.396 \\
\hline & -3.5 & -3 & 0.42 \\
\hline & -3 & -3.5 & 0.396 \\
\hline & -3 & -3 & 0.42 \\
\hline$\frac{\theta}{\theta}$ & -3 & -1.5 & 0.437 \\
\hline$\Sigma$ & -3 & -1 & 0.46 \\
\hline F्. & -3 & 2 & 0.5 \\
\hline & -3 & 3.5 & 0.467 \\
\hline & -3 & 4 & 0.46 \\
\hline & -3 & 5 & 0.46 \\
\hline & -2 & -5 & 0.42 \\
\hline & -2 & -3 & 0.46 \\
\hline & -2 & -1 & 0.5 \\
\hline & -2 & 2 & 0.46 \\
\hline & -2 & 5 & 0.42 \\
\hline & -1 & 1 & 0.5 \\
\hline & -1 & 5 & 0.42 \\
\hline & 1 & 4 & 0.34 \\
\hline & 2 & 1 & 0.42 \\
\hline & 3 & 4 & 0.38 \\
\hline
\end{tabular}

The outcome of ANFIS approach is shown in Fig. 8, from which it can be seen that specific set of rules is formed by different combinations of input variables and output.

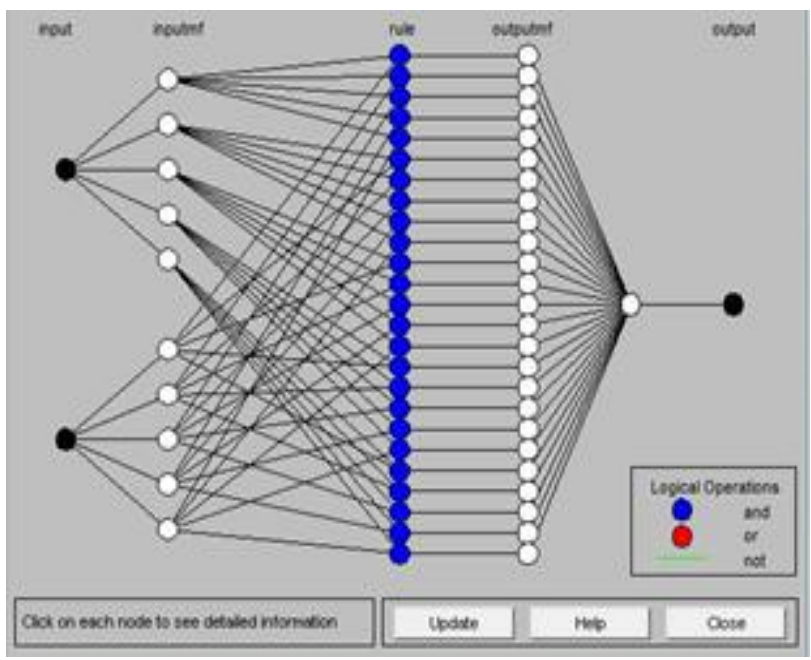

Fig. 8: Output Structure of ANFIS technique

Simulation has been done by inserting this ANFIS technique in control system and gains of appropriate values are used as shown in in Fig. 9.

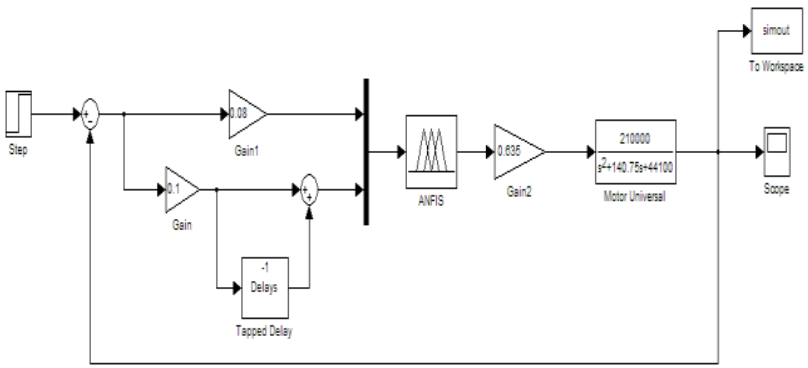

Fig. 9: ANFIS Model for Universal Motor

The output response of the system is shown in Fig 10, which has a certain value of overshoot and rise time.

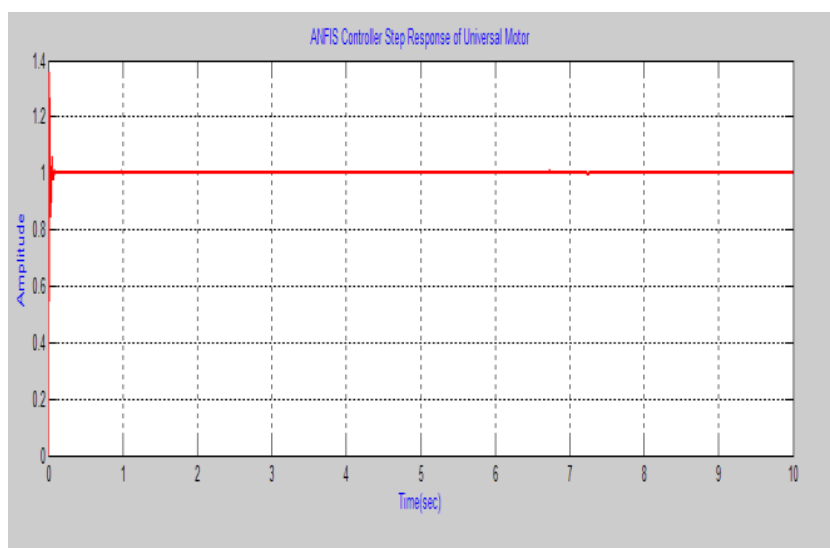

Fig 10: Response for Universal Motor

The comparison analysis between Fuzzy and ANFIS approach is shown in TABLE III.

Table III Comparative Analysis between Fuzzy and ANFIS Controller

\begin{tabular}{|c|c|c|}
\hline Parameter & Fuzzy & ANFIS \\
\hline $\begin{array}{c}\text { Percentage } \\
\text { Overshoot }\end{array}$ & $29.6 \%$ & $28.3 \%$ \\
\hline Rising Time & $0.841 \mathrm{sec}$ & $1.148 \mathrm{sec}$ \\
\hline
\end{tabular}

\section{CONCLUSION}

This research work includes a comparative analysis of controlling speed of universal motor using two different types of approaches. This research is done basically to investigate the best approach to be incorporated in required applications. This will definitely lead to an initial step towards study of driving newer technologies. This research work has first interpreted fuzzy and ANFIS approach separately for controlling speed of universal motor. After that a comparison is made between the two approaches on the basis of overshoot and rising time of their output signals to analyse which approach can be devised in industry for any required application because percentage overshoot and rising time are two basic parameters to be considered when controlling the speed of the machine. Designing of most of the systems require reduction of percentage overshoot and rising time as much as we can to produce minimum distortion of the output signal. In this research work, ANFIS controller has produced a percentage overshoot of $28.3 \%$ which is about $1.3 \%$ less than that of percentage overshoot of Fuzzy controller which is $29.6 \%$. Hence we can conclude that ANFIS controller is a better approach to be employed in required applications than 
Fuzzy controller when considering percentage overshoot of both techniques. However, ANFIS gives a rising time of $0.307 \mathrm{sec}$ than that of Fuzzy controller which is the drawback of using ANFIS controller but due to its less percentage overshoot, it should be considered a much better approach than Fuzzy controller. Further research work can be done for minimizing rising time of ANFIS controller and producing effectual and unimpeachable systems.

\section{REFERENCES}

[1] Basma A. Omar, Amira Y. Haikal, Fayz F. Areed, "An Adaptive Neuro-Fuzzy Speed Controller for a separately excited DC Motor," International Journal of Computer Applications (0975 - 8887) Vol. 39- No.9, February 2012

[2] Malkeet Saini and Neeraj Sharma, "Speed Control of Separately excited D.C Motor Using Computational Method", International Journal of Engineering Research \& Technology (IJERT), Vol. 1 Issue 7, September 2012

[3] Salim, Jyoti Ohri, Naveen, "Speed Control of DC Motor using Fuzzy Logic based on LabVIEW", International Journal of Scientific and Research Publications, Volume 3, Issue 6, June 2013

[4] V. Chitra, and R. S. Prabhakar, "Induction Motor Speed Control using Fuzzy Logic Controller", World Academy of Science, Engineering and Technology 232006

[5] Jaime Fonseca, João L. Afonso, Júlio S. Martins, Carlos Couto, "Fuzzy logic speed control of an induction motor", Microprocessors and Microsystems 22 (1999) $523-534$

[6] Ashok Kusagur, Shankarappa Fakirappa Kodad, Sanker Ram, "Modelling \& Simulation of an ANFIS controller for an AC drive", World Journal of Modelling and Simulation Vol. 8 (2012) No. 1, pp.36-49

[7] L.Barazane, M. Laribi and R. Ouiguini, "ANFIS Speed Controller for Vector Control of An Induction Motor",
International Symposium on Environment Friendly Energies in Electrical Applications 2-4 November 2010, Ghardaïa, Algeria

[8] Ashok Kusagur, Dr. S. F. Kodad, Dr. B V. Sankar Ram, "Modeling, Design \& Simulation of an Adaptive NeuroFuzzy Inference System (ANFIS) for Speed Control of Induction Motor", International Journal of Computer Applications (0975 - 8887) Volume 6- No.12, September 2010

[9] Sung-Hoe Huh, Kyo-Beum Lee, Dong-Won Kim, Ick Choy, and Gwi-Tae Park, "Sensorless Speed Control System Using a Neural Network", International Journal of Control, Automation, and Systems, vol. 3, no. 4,pp. 612-619, December 2005

[10] Amit Atri, Md. Ilyas, "Speed Control of DC Motor using Neural Network Configuration", International Journal of Advanced Research in Computer Science and Software Engineering, Volume 2, Issue 5, May 2012

[11] Ashutosh Mishra, Prashant Choudhary "Artificial Neural Network Based Controller for Speed Control of an Induction Motor using Indirect Vector Control Method", International Journal of Power Electronics and Drive System (IJPEDS) Vol.2, No.4, December 2012, pp. 402408

[12] C. Mohan Krishna M. Tech, G. Meerimatha M.Tech, U. Kamal Kumar M. Tech, "Indirect Vector Control of Induction Motor Using Pi Speed Controller and Neural Networks", International Journal of Modern Engineering Research (IJMER) Vol.3, Issue.4, Jul - Aug. 2013 pp1980-1987

[13] Om Prakash Verma, Himanshu Gupta, "Fuzzy Logic Based Water Bath Temperature Control System", International Journal of Advanced Research in Computer Science and Software Engineering (IJARCSSE), Volume 2, Issue 4, April 2012 